\title{
Hot flushes still occur in a population of 85- year-old Swedish women
}

Josefin Vikström, Anna-Clara Spetz, Gunilla Sydsjö, Jan Marcusson, Ewa Wressle and Mats

Hammar

\section{Linköping University Post Print}

N.B.: When citing this work, cite the original article.

Original Publication:

Josefin Vikström, Anna-Clara Spetz, Gunilla Sydsjö, Jan Marcusson, Ewa Wressle and Mats Hammar, Hot flushes still occur in a population of 85-year-old Swedish women, 2013, Climacteric, (16), 4, 453-459.

http://dx.doi.org/10.3109/13697137.2012.727199

Copyright: Informa Healthcare

http://informahealthcare.com/

Postprint available at: Linköping University Electronic Press

http://urn.kb.se/resolve?urn=urn:nbn:se:liu:diva-96983 


\section{Hot flushes still occur in a population of 85-year old Swedish women}

Running title: Flushes in older women.

Key words: menopause, hot flashes, old age, hormone therapy

Josefin Vikström MD ${ }^{\text {,b,§ }}$, Anna-Clara Spetz Holm, MD, PhD ${ }^{\mathrm{a}, \mathrm{b}}$, Gunilla Sydsjö, $\mathrm{PhD}^{\mathrm{a}, \mathrm{b}}$, Jan Marcusson, MD, PhD ${ }^{\mathrm{c}, \mathrm{d}}$, Ewa Wressle, $\mathrm{PhD}^{\mathrm{c}, \mathrm{d}}$ and Mats Hammar, MD, $\mathrm{PhD}^{\mathrm{a}, \mathrm{b}}$

${ }^{a}$ Faculty of Health Sciences, Department of Clinical and Experimental Medicine

Division of Obstetrics and Gynecology, Linköping University, SE-581 85 Linköping,

Sweden

${ }^{\mathrm{b}}$ Department of Obstetrics and Gynecology, County Council of Östergötland, SE-581

85 Linköping, Sweden

${ }^{\mathrm{c}}$ Faculty of Health Sciences, Department of Clinical and Experimental Medicine

Division of Geriatrics, Linköping University, SE-581 85 Linköping, Sweden

${ }^{\mathrm{d}}$ Department of Geriatrics, County Council of Östergötland, Linköping, Sweden

$\S$ Corresponding author

Email addresses: JV: josvi752@student.liu.se, AH: anna-clara.spetz.holm@liu.se, MH:

mats.hammar@liu.se, JM: jan.marcusson@liu.se, EW: ewa.wressle@lio.se, GS:

gunilla.sydsjo@lio.se

Reprint requests and correspondence: Josefin Vikström, Obstetrics and Gynaecology, Department of Clinical and Experimental Medicine, Faculty of Health Sciences, University Hospital, SE-581 85 Linköping, Sweden, e-mail: josvi752@student.liu.se, telephone +46703320527 . 


\begin{abstract}
Objectives: Hot flushes and night sweats often cause discomfort and may negatively affect sleep and quality of life. Studies have shown that menopausal symptoms, like hot flushes, may persist for up to 20 years after the menopausal transition, but there are no published studies regarding the occurrence of hot flushes among women older than 80 years. The aim of this study is to determine the prevalence of hot flushes in 85-year old women.
\end{abstract}

Methods: All 85-year old women living in Linköping municipality in $2007(n=415)$ received a postal questionnaire. The majority, $74 \%(n=307)$, answered the questionnaire and $47 \%$ ( $n=194)$ agreed to visit the Department of Geriatric Medicine during which questions regarding hot flushes and use of hormone therapy were asked.

Results: About 16\% ( $\mathrm{n}=29)$ of the women experienced hot flushes during the day and/or during the night and 6.5\% $(\mathrm{n}=12)$ of the women were currently using hormone therapy $(\mathrm{HT})$. Almost 1/10 $(\mathrm{n}=17)$ out of all responding women were very to moderately distressed by their hot flushes.

Discussion: Our results confirm and extend previous knowledge based on studies of younger postmenopausal women in showing that menopausal symptoms still occur in elderly women. We found that while the prevalence of menopausal symptoms decreases with age, these symptoms are still experienced by some 85-year old women. 


\section{Introduction}

According to both cross sectional and prospective studies, $50-75 \%$ of women in the western world report hot flushes and sweating when going through the menopause [1-3]. These symptoms often cause discomfort and may negatively affect night sleep and quality of life. Apart from hot flushes and night sweats, vaginal dryness and dyspareunia are the only symptoms that have been proven to be associated with the endocrine changes around the menopause [1-4].

Hot flushes can persist for many years; about $20 \%$ of women are still troubled by hot flushes 10 to 20 years after the menopause $[1,5]$. In line with these results, Barnabei et al (2002) analysed data from the Heart and Estrogen/Progestin Replacement Study and found that almost $20 \%$ of women aged $70-74$ years reported very frequent or frequent hot flushes [6] while Rödström et al (2002) reported a lower number, that only 9\% of the 72-year old women were troubled by hot flushes [7]. A recent large cohort study [8] on 202638 postmenopausal women showed that menopausal symptoms were still present in 54\% 10 years after menopause and that the symptoms and their frequency remained constant from 55 to 65 years of age. The authors concluded that previous studies may have underestimated the duration of menopausal symptoms. The study also showed that the reported frequency of menopausal symptoms were related to hysterectomy, anxiety and depression, smoking, alcohol use, HT use, education, BMI and skirt size increases [8].

It is not possible to compare different populations, however there are thus few published studies about menopausal symptoms in women over the age of 80 . The clinical experience is, however, that many women ask about how long menopausal symptoms may persist. We therefore found it important to find out if menopausal symptoms still occur in 85year old women. In this study we analyse data from the ELSA 85 population study, in which 
all 85-year old individuals living in Linköping municipality, Sweden, in 2007 were invited to participate. The aim of this study was to assess the prevalence and severity of hot flushes in 85-year old women in Linköping, Sweden.

\section{Methods}

The analyses are based on data from the Elderly in Linköping Screening Assessment, ELSA 85, a population study of 85-year olds living in Linköping, Sweden. The purpose of the ELSA 85 study is to learn more about this population, which often suffers from multiple chronic illnesses and requires large amounts of healthcare resources.

\section{Participants}

In 2007, a postal questionnaire was sent to all individuals born in 1922 and who lived in Linköping municipality. Linköping is a university city in southeast Sweden consisting of mainly urban inhabitants but also some rural areas. In 2007, Linköping municipality had 140367 inhabitants [9]. The names and addresses of the eligible participants were obtained from the Swedish population register. Information about the nature of the study was included in the postal questionnaire, and also that all data were to be treated confidentially, options for participation in each phase of the study and the choice not to participate at all. A selfaddressed envelope was enclosed for the written consent, which was a requirement for participation in the study.

In 2007 there were 415 85-year old women living in Linköping municipality. Out of these, 74 percent $(n=307)$ answered the postal questionnaire, some by themselves and some by the help of a dependant or caretaker. $54 \%(n=223)$ agreed to an interview conducted in the 
participants' home and 47\% (n=194) also participated in the third step, a visit at the Department of Geriatric Medicine. Further information about participation and drop-outs can be found in the enclosed flow chart (figure 1). For further information about the purpose and background of the ELSA 85 study we refer to a recently published article on the topic [10].

\section{Background variables}

The postal questionnaire included one question regarding marital status with response alternatives 1 “Married/cohabiting”, 2 “Unmarried” and 3 “Widow/widower”. Included was also a question regarding highest level of education achieved with response alternatives 1 “Elementary school”, 2 “Secondary grammar school” and 3 “University”.

Housing was examined using the response alternatives 1 “Apartment”, 2 “House”, 3 “Residential care”, 4 "Nursing home”, 5 "Nursing home for individuals with dementia”. For the sake of simplicity alternatives 1 and 2 were summarized and recoded into 1 "Independent housing” and the other alternatives into 2 "Institutional housing”.

Questions regarding use of tobacco had the response alternatives 1 "Smoker”, 2 "Nonsmoker”, 3 “Ex-smoker” where alternatives 2 and 3 were summarized and recoded into 2 "Non-smoker". The response alternatives for the question regarding alcohol were 1 "Rarely", 2 "Regularly”, 3 "Never”, where alternatives 1 and 2 were summarized and recoded into 1 "Yes".

The participants were also asked to state their height and weight for calculation of body mass index (BMI). To simplify interpretation of the chi2-tests, the BMI-values were divided into two categories; 1 " $\leq 24.9$ ” and 2 " $\geq 25.0$ ” g/L.

The postal questionnaire also included a question regarding age at menopause. The values were divided into four categories; 1 “ $\leq 44$ ”, 2 “45-49”, 3 “50-54” and 4 “ $\geq 55$ ”. 
Hot flushes and use of hormone therapy

During the visit at the Department of Geriatric Medicine, Linköping University Hospital, questions regarding menopausal symptoms and hormone therapy (HT) were asked and blood samples were taken. The occurrence of hot flushes was investigated using the following questions: "Do you sometimes experience hot flushes or sweats during the day?” and "Do you sometimes experience hot flushes and sweats at night?" with response alternatives “never”, “a couple of times per week” and “several times per day” for both questions. For the chi square tests of the distribution of the background variables these response alternatives were recoded into "No flushes" and "flushes". We also asked the question: “To what extent are you distressed by your hot flushes or sweats?” with response alternatives "very”, “moderately”, "not much” and "not at all”. The use of HT was investigated using the questions: "Are you currently using estrogen-based treatment for your hot flushes or sweats?", with response alternatives "No" and "Yes".

\section{Co-morbidity}

In the postal questionnaire, questions regarding current medication and diseases including neurological, gastrointestinal, cardiovascular, urological, endocrinological, haematological, immunological, infectious and psychiatric were asked as well as dementia, hypertension, hypotension, diabetes mellitus, stroke and cancer. The response alternatives for these questions were "Yes” and “No".

\section{Blood samples}


Blood samples were drawn from women who participated in the third step, a visit at the Department of Geriatric Medicine and were analysed consecutively. All individuals who had responded to the questions regarding menopause agreed to have blood tests taken. Thyroid Stimulating Hormone (TSH) was analysed according to the clinical routine at the department of Clinical Chemistry, University Hospital of Linköping. The values were divided into three categories; low (<.4), normal (.4-4.0) and high (>4.0).

\section{Statistics}

Statistical analyses were performed using SPSS 17.0 (SPSS, Chicago, USA). Chisquare tests were used with the purpose to find significant differences in the distribution of background variables across the groups (flushes, no flushes). For these analyses, having hot flushes was defined as binary variable taking on the value of 1 (yes) and 0 (no). In the case of small sample sizes $(<5)$ Fisher's exact test was used. The background variables included were marital status, housing, education, use of alcohol and tobacco, BMI and age at menopause.

The participants' characteristics regarding symptoms and treatment of menopause are reported as percent or means. Chi-square tests were used to discover overlaps between "hot flushes during the day" and "hot flushes during the night" respectively and "the use of HT", "hot flushes during the day” and "hot flushes during the night” respectively. Logistic regression analyses were performed in order to investigate the influence of a number of factors on the occurrence of hot flushes. The factors used were known differential diagnoses of hot flushes [11] that were included in the ELSA 85 study: tobacco and alcohol use, body mass index, age at menopause, current cancer disease, hypotension, anxiety syndrome, antihypertensive therapy, use of HT, nitro-glycerine, thyroid-related drugs, TSH and use of antidepressants. For these analyses, having hot flushes was defined as binary variable taking 
on the value of 1 (yes) and 0 (no). Chi-square tests were performed in order to discover differences between the third step participants and non-participants in regards to sociodemographic factors and co-morbidity. The individuals included in the group "nonparticipants” had previously participated in the study but had declined participation in the third part of the study when questions regarding menopausal symptoms were asked.

\section{Ethics}

The study was approved by the Regional Ethics Board at the Faculty of Health Sciences, Linköping University (\$141-06).

\section{Results}

Out of the 415 women living in Linköping municipality in 2007, 47\% (n=194) participated in the third step of the ELSA 85 study, the visit at the Department of Geriatric Medicine, during which all questions regarding hot flushes were asked. Among these 194 women, 179 (92.2\%) had answered the postal questionnaire by themselves while 15 (7.8\%) had received help from a caregiver or a dependant. The number of women who responded to the different questions regarding menopausal symptoms ranged from 174 to 184 . The mean age at reported menopause was 49.5 years and thus an average of 35.5 years had passed since the menopausal transition.

\section{Participants}

As it is shown in table 1 , the majority of the participants $(n=169,91.8 \%)$ were living in independent housing and had only finished elementary school (n=140, 76.1\%), 96.7\% 
$(n=178)$ were non-smokers and the majority used alcohol $(n=105,57.1 \%)$. In regards to these variables, as well as the variables BMI and marital status we found no statistically significant differences between the group with and without flushes day and/or night.

Women still experiencing hot flushes were significantly more likely than those without flushes to have reached menopause before 50 years of age, while those without current hot flushes were more likely to have reached menopause at age 50-54 (table 1).

\section{Hot flushes}

Hot flushes during the day and/or the night at least a couple of times per week were experienced by $15.9 \%(n=29)$ of the responding women and several times per day and/or night by 3.8\% (n=7) of the women. Only one of these women received HT. Twelve women (6.5\%) reported being troubled by hot flushes both during the day and the night whereas slightly more women ( $\mathrm{n}=17$ ) were troubled by hot flushes only during the daytime (table 2). Approximately 1/3 $(n=5)$ of these women experienced hot flushes several times per day. About $13 \%(n=24)$ of the women reported being troubled by hot flushes during the night (table 2) and approximately 1/4 of these women experienced hot flushes several times per night $(n=6)$. A majority of the responding women stated that they were not at all troubled by hot flushes or that the question was not applicable to them. However, almost one tenth $(\mathrm{n}=17)$ of the women were very to moderately distressed by their hot flushes (table 2). HT was currently used by $6.5 \%(n=12)$ of the responding women. One of these women reported being troubled by hot flushes. Therefore in all $22 \%(n=40)$ of the women reported either being troubled by hot flushes or were using HT.

\section{Co-factors}


We performed logistic regression analyses in order to investigate the influence of a number of factors on the occurrence of hot flushes. Women who experienced hot flushes during the day were more likely to use nitroglycerine therapy than those who did not have flushes ( $\mathrm{p}=.022 ; 95 \% \mathrm{CI}$.097-.836) and those who experienced flushes were more likely to have reached menopause at an earlier age ( $\mathrm{p}=.23$; 95\% CI .762-.980). No differences were found between the groups with respect to tobacco and alcohol use, BMI, age at menopause, current cancer disease, hypotension, anxiety syndrome, thyroid illness, anti-hypertensive therapy, use of HT or thyroid-related drugs, levels of TSH and use of antidepressants. The distribution of confounding variables among the women who experienced flushes during the day and/or night can be found in table 3.

Chi-square tests were performed in order to determine if there were any existing differences between the third step participants and the non-participants in regards to sociodemographical factors and co-morbidity. We found that the non-participants were significantly more likely than the participants to be living in nursing homes while the participants were more likely to live in independent housing. The participants were significantly more likely to use alcohol than were the non-participants, whereas we found no differences in regards to marital status, education or tobacco use.

In regards to co-morbidity, the non-participants were significantly more likely to have a neurological disease and dementia while the participants were more likely to suffer from respiratory, gastrointestinal, urogenital, musculoskeletal, haematological, immunological, infectious disease, hypertension, hypotension, stroke and diabetes mellitus. No differences were found in regards to cancer, endocrinological, cardiovascular or psychiatric disease.

To determine the cause of these differences a chi-square test was performed to determine statistically significant differences between the participants and the nonparticipants in regards to who had answered and filled in the questionnaire. While $85.5 \%$ of 
the third step participants had answered the questionnaire by themselves, the corresponding number was $51,6 \%$ for the non-participants.

\section{Discussion}

Our results show that about every sixth $(n=29,15.9 \%)$ 85-year old woman experienced hot flushes during the day and/or during the night. Almost one tenth of the women $(n=17$, 9.8\%) were moderately to very distressed by their hot flushes. These results are in accordance with those of Barnabei et al. [6], Rödström et al. [7] and Hunter at al [8] who reported that menopausal symptoms still occur in elderly women and strengthens the hypothesis posed by Hunter et al [8]; that the duration of menopausal symptoms may have been underestimated previously. While Barnabei et al. [6] found that 20\% of women aged $70-74$ years were troubled by hot flushes, we found a slightly lower prevalence among the 10 to 15 years older participants of our study. This is reasonable since menopausal symptoms seem to decrease with age. On the other hand, we found a greater prevalence of hot flushes than did Rödström et al. [7], even though the women included in our study were 13 years older than those in their oldest age cohort. The reason for this difference might be the manner in which the questions regarding hot flushes were posed. Our questions included multiple response alternatives while Rödström et al. [7] only had two response alternatives, “yes” and “no”. In contrast to us, Rödström et al. [7] excluded the women with surgical menopause. Since we did not have any knowledge on whether the menopause was surgical or natural this factor could not be included in our analyses. This fact, however, should not significantly affect the results, because only about 10 percent of a Swedish female population has undergone hysterectomy and/or oophorectomy according to previous data, including cohorts born around 1930 [1, 5]. 
It could be argued that the flushes reported by the 85 years old women could have been caused by something other than menopause and decreased sex steroid production. The cross sectional design used by us does of course not prove an association between the flushes and the menopause transition. We have, however, controlled that a number of factors which could cause hot flushes [11] were not more prevalent in the flushing women than in the non-flushing women. Ideally we should have asked the women in greater detail if the flushes had been ongoing all the time since menopause, something which, unfortunately, was not done. The response rate for this study was only $47 \%$, which is a major limiting factor and might be the reason why some associations found in other studies were not found here. It is also possible that the non-participants were more or less likely than the participants to be troubled by hot flushes, making our conclusions less certain.

There was a large difference in the group sizes between those who experienced hot flushes compared to those who did not. However, this should not have a negative effect on the validity of our results since Fisher's exact test was used to calculate differences when the group sizes were $\leq 5$.

Since 12 women (6.5\%) used HT and only one of those women reported hot flushes the percentage of women still distressed by hot flushes is likely to have been even greater than 15.9\% ( $\mathrm{n}=29$ ), had they not used HT. Assuming that the purpose of using HT among all the 85-year old women who reported use of HT was to reduce the occurrence of menopausal symptoms, more than one out of five $(21.9 \%, n=40)$ of the 85 -year old women could still be distressed by hot flushes had they not used HT. Unfortunately, we have no knowledge of the time span of the use of HT medication and we also lack information of why HT was started in the beginning. Hence we cannot be sure that it was not for other reasons than hot flushes. 
There was a statistically significant difference in the distribution of use of nitroglycerin therapy between women experiencing hot flushes during the day and those who did not. Nitroglycerin is a vasodilator and vasodilation is a component of flushing. Therefore it is not surprising that the women who reported being troubled by hot flushes were more likely to use nitroglycerin than were those who were not troubled by hot flushes. Other types of medications may also interfere with the occurrence of hot flushes, for example antihypertensive medicines and antidepressants [12,13]. We have included these categories of medicines in our logistic regression analyses. Unfortunately we did not have any information about the specific type of medication used There was also a statistically significant difference between those who were experiencing hot flushes and those who were not in regards to age at menopause. It appears that those who had reached menopause at an earlier age were more likely to still be troubled by hot flushes.

While the participants in the third step of the study were more likely to live in independent housing, the non-participants were more likely to live in nursing homes and to suffer from neurological disease and dementia. Judging from these differences, the nonparticipants appear to be frailer than were the participants which might explain why the nonparticipants did not participate in the third part of the study, the visit at the Department of Geriatric Medicine. Surprisingly, the participants were significantly more likely to suffer from a multitude of diseases. One possible reason for this might be the fact that the participants more often had answered the questionnaire by his- or herself than had the non-participants. The dependants or caretakers who answered the questionnaire for the non-participants might not be aware of all her diseases.

\section{Conclusions}


In conclusion, about one out of six $(15.9 \%, n=29) 85$ year old women were still distressed by hot flushes on average more than 30 years after menopause. More research is needed to increase the knowledge about the prevalence of menopausal symptoms in elderly women and to determine the most effective treatment regime for these women. Unfortunately we were unable to identify factors predicting which women will have long-standing symptoms and which will not. It is important that providers of healthcare are aware of the fact that hot flushes may still occur in 85-year old women and that these women may benefit from treatment of menopausal symptoms.

Acknowledgements: We are thankful for statistical advice from Marie Bladh. 


\section{References}

[1] Hammar M, Berg G, Fåhraeus L, Larsson-Cohn U. Climacteric symptoms in an unselected sample of Swedish women. Maturitas 1984; 6: 345-50.

[2] McKinlay SM, Brambilla DJ, Posner JG. The normal menopause transition. Maturitas 1992;14:103-15.

[3] Stadberg E, Mattsson L-Å, Milsom I. The prevalence and severity of climacteric symptoms and the use of different treatment regimens in a Swedish population. Acta Obstet Gynecol Scand 1997; 76: 442-8.

[4] Iosif CS, Becassy Z. Prevalence of genito-urinary symptoms in the late menopause. Acta Obstet Gynecol Scand 1984; 63: 257-260.

[5] Berg G, Gottvall T, Hammar M, Lindgren R. Climacteric symptoms among women aged 60-62 in Linköping, Sweden, in 1986. Maturitas 1988; 10:193-199.

[6] Barnabei V, Grady D, Stovall D, et al. Menopausal symptoms in older women and the effects of treatment with hormone therapy. Obstet Gynecol 2002; 100:1209-18.

[7] Rödström K, Bengtsson C, Lissner L, Milsom I, Sundh V, Björkelund C. A longitudinal study of the treatment of hot flushes: the population study of women in Gothenburg during a quarter of a century. Menopause 2002; 9: 156-161.

[8] Hunter MS, Gentry-Maharaj A, Ryan A, Burnell M, Lanceley A, Fraser L, Jacobs I, Menonb U. Prevalence, frequency and problem rating of hot flushes persist in older postmenopausal women: impact of age, body mass index, hysterectomy, hormone therapy use, lifestyle and mood in a cross-sectional cohort study of 10418 British women aged 54-65. BJOG 2012; 119:40-50.

[9] Scb.se [Internet]. Stockholm: Statistiska centralbyrån [updated 2009 Feb 17; cited 2010 Jan 21] Avaliable from: www.scb.se. 
[10] Nagga K, Dong H, Marcusson J, Skoglund S, Wressle E. Health-related factors

associated with hospitalization for old people: Comparisons of elderly aged 85 in a population cohort study. Arch Gerontol Geriatr, in press.

[11] Mohyi D, Khosrow T, Simon J. Differential diagnosis of hot flushes. Maturitas 1997;

27: 203-214.

[12] Carroll DG, Kelley KW. Use of antidepressants for management of hot flashes.

Phamacotherapy 2009; 29: 1357-74.

[13] Rada G, Capurro D, Pantoja T et al. Non-hormonal interventions for hot flushes in women with a history of breast cancer. Cochrane Database Syst Rev. 2010 Sep

8;(9):CD004923.

Financial support: This work was supported by grants from The Health Research Council in the South-East of Sweden (grant numbers FORSS-8888, FORSS-11636, FORSS-31811); the County of Östergötland (LIO-11877, LIO-31321, LIO-79951) and the Family Janne Elgqvist Foundation. 
Table 1. Sample characteristics.

Table 1. Sample characteristics

\begin{tabular}{cccccr}
\multicolumn{1}{c}{ Total } & No flushes & \multicolumn{2}{c}{ Flushes } \\
n & $\% *$ & n & $\% *$ & n & $\% *$ \\
184 & 100 & 155 & 84.2 & 29 & 15.8
\end{tabular}

\section{Independent variables}

\section{Housing}

Independent

$\begin{array}{llllll}169 & 91.8 & 143 & 92.3 & 26 & 89.7\end{array}$

Institutional

$\begin{array}{llllll}15 & 8.2 & 12 & 7.7 & 3 & 10.3\end{array}$

$.697 *$

\section{Marital status}

$\begin{array}{lrrrrrr}\text { Married } & 54 & 29.3 & 43 & 27.7 & 11 & 37.9 \\ \text { Unmarried } & 20 & 10.9 & 17 & 11.0 & 3 & 10.3 \\ \text { Widowed } & 110 & 59.8 & 95 & 61.3 & 15 & 51.7\end{array}$

$.536 *$

\section{Education}

$\begin{array}{lcccccc}\text { Elementary school } & 140 & 76.1 & 115 & 74.2 & 25 & 86.2 \\ \text { Secondary grammar school } & 35 & 19.0 & 33 & 21.3 & 2 & 6.9 \\ & 9 & 9.0 & 7 & 4.5 & 2 & 6.9\end{array}$

Tobacco use

Smoker

$$
\begin{array}{llllll}
6 & 3.3 & 4 & 2.6 & 2 & 3.3
\end{array}
$$

Non-smoker

$\begin{array}{llllll}178 & 96.7 & 151 & 97.4 & 27 & 96.7\end{array}$




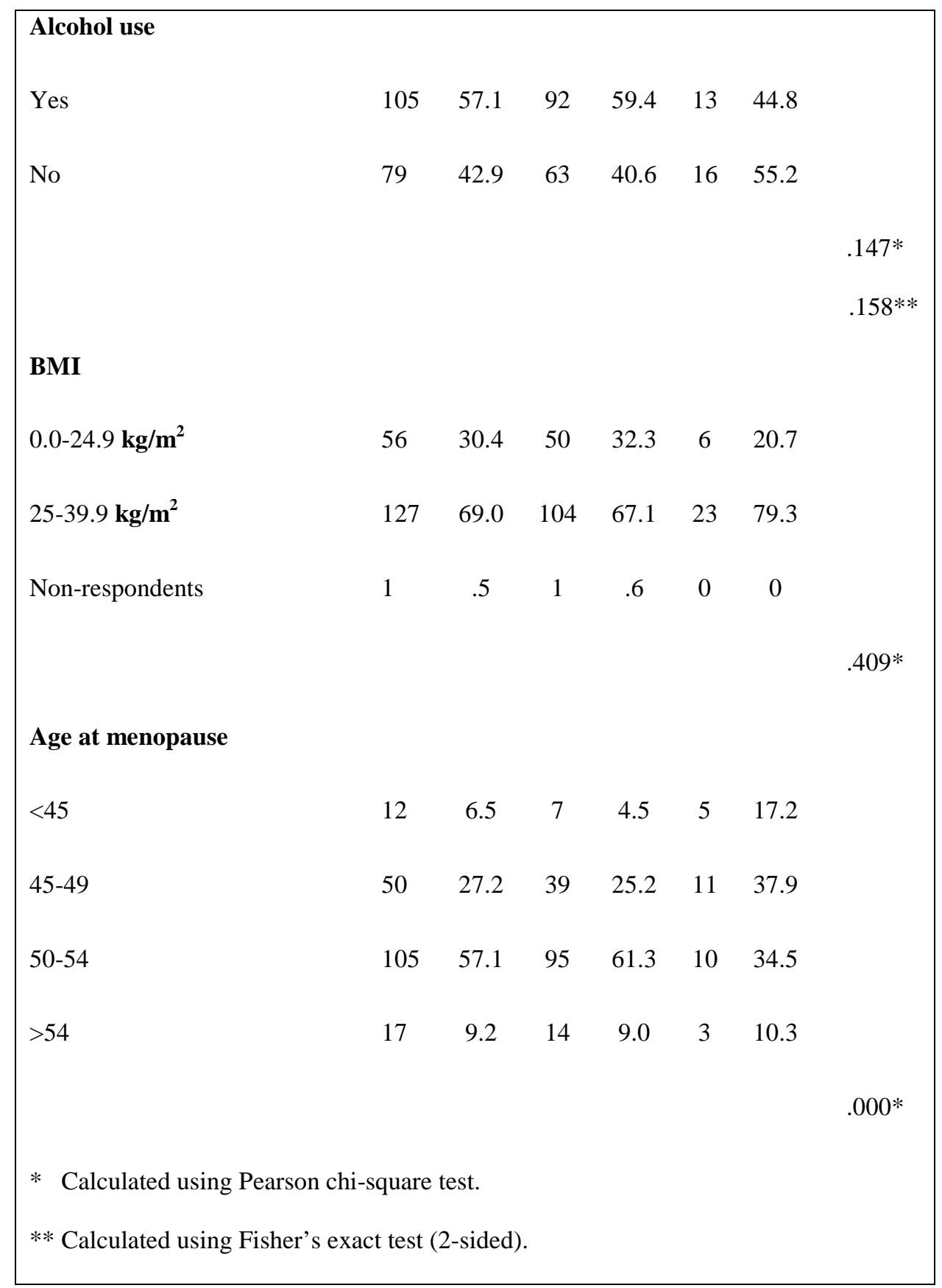


Table 2. Prevalence of, and extent of problems caused by, hot flushes

\begin{tabular}{|lcc|}
\hline \multicolumn{2}{|c|}{ Table 2. Prevalence of, and extent of problems caused by, hot flushes } \\
n
\end{tabular}


Table 3. The distribution of confounding factors for flushes among the flushing women Table 3. The distribution of confounding
factors for flushes among the flushing women

\begin{tabular}{|c|c|c|}
\hline & $\mathrm{n}$ & $\%$ \\
\hline \multicolumn{3}{|l|}{ Use of tobacco } \\
\hline Yes & 2 & 6.9 \\
\hline No & 27 & 93.1 \\
\hline \multicolumn{3}{|l|}{ Use of alcohol } \\
\hline Yes & 13 & 44.8 \\
\hline No & 16 & 55.2 \\
\hline \multicolumn{3}{|l|}{ BMI } \\
\hline $0.0-24.9 \mathrm{~kg} / \mathrm{m}^{2}$ & 6 & 20.7 \\
\hline$>25 \mathrm{~kg} / \mathrm{m}^{2}$ & 23 & 79.3 \\
\hline \multicolumn{3}{|l|}{ Age at menopause } \\
\hline$<45$ & 5 & 17.2 \\
\hline $45-49$ & 11 & 37.9 \\
\hline $50-54$ & 10 & 34.5 \\
\hline$>54$ & 3 & 10.2 \\
\hline \multicolumn{3}{|l|}{ Current cancer disease } \\
\hline Yes & 2 & 6.9 \\
\hline No & 27 & 93.1 \\
\hline \multicolumn{3}{|l|}{ Hypotension } \\
\hline Yes & 2 & 6.9 \\
\hline No & 27 & 93.1 \\
\hline \multicolumn{3}{|l|}{ Anxiety disorder } \\
\hline Yes & 3 & 10.3 \\
\hline No & 26 & 89.7 \\
\hline \multicolumn{3}{|l|}{$\begin{array}{l}\text { Antihypertensive } \\
\text { medicine }\end{array}$} \\
\hline Yes & 19 & 65.5 \\
\hline No & 10 & 34.5 \\
\hline
\end{tabular}




\begin{tabular}{|l|c|c|}
\hline & & \\
\hline Hormone therapy & & \\
\hline Yes & 1 & 3.4 \\
\hline No & 28 & 96.6 \\
\hline & & \\
\hline Nitroglycerine & & \\
\hline Yes & 10 & 34.5 \\
\hline No & 19 & 65.5 \\
\hline Thyroid-related & & \\
\hline medicine & & \\
\hline Yes & 6 & 20.7 \\
\hline No & 23 & 79.3 \\
\hline Antidepressants & & \\
\hline Yes & 6 & 20.7 \\
\hline No & 23 & 79.3 \\
\hline & & \\
\hline TSH & & \\
\hline$<.4$ & & 10.3 \\
\hline $.4-4.0$ & & 80.4 \\
\hline$>4.0$ & & \\
\hline & & \\
\hline & & \\
\hline & & \\
\hline
\end{tabular}

